Article

\title{
Immunogenicity of Non-Living Anthrax Vaccine Candidates in Cattle and Protective Efficacy of Immune Sera in A/J Mouse Model Compared to the Sterne Live Spore Vaccine
}

\author{
Solomon Jauro ${ }^{1,2, *}$, Okechukwu C. Ndumnego ${ }^{3}\left(\mathbb{D}\right.$, Charlotte Ellis 4 , Angela Buys ${ }^{4}$, \\ Wolfgang Beyer ${ }^{5}$ iD and Henriette van Heerden ${ }^{1}$ (D) \\ 1 Department of Veterinary Tropical Diseases, Faculty of Veterinary Science, University of Pretoria, \\ Onderstepoort, Pretoria 0110, South Africa; henriette.vanheerden@up.ac.za \\ 2 Department of Veterinary Microbiology, Faculty of Veterinary Medicine, University of Maiduguri, \\ Maiduguri 600230, Nigeria \\ 3 Moredun Scientific, Pentlands Science Park, Edinburgh EH26 0PZ, UK; \\ o.ndumnego@moredun-scientific.com \\ 4 Design Biologix, Building 43b CSIR, Meiring Naude Road, Brummeria 0184, South Africa; \\ charlotte@designbio.co.za (C.E.); angela@designbio.co.za (A.B.) \\ 5 Department of Livestock Infectiology and Environmental Hygiene, Institute of Animal Science, \\ University of Hohenheim, Stuttgart 70599, Germany; wolfgang.beyer@uni-hohenheim.de \\ * Correspondence: sjauro@unimaid.edu.ng
}

Received: 5 June 2020; Accepted: 29 June 2020; Published: 10 July 2020

check for updates

\begin{abstract}
The Sterne live spore vaccine (SLSV, Bacillus anthracis strain 34F2) is the veterinary vaccine of choice against anthrax though contra-indicated for use with antimicrobials. However, the use of non-living anthrax vaccine (NLAV) candidates can overcome the SLSV limitation. In this study, cattle were vaccinated with either of the NLAV (purified recombinant PA (PrPA) or crude rPA (CrPA) and formaldehyde-inactivated spores (FIS of B. anthracis strain 34F2) and emulsigen- $\mathrm{D}^{\circledR} /$ alhydrogel ${ }^{\circledR}$ adjuvants) or SLSV. The immunogenicity of the NLAV and SLSV was assessed and the protective efficacies evaluated using a passive immunization mouse model. Polyclonal IgG (including the IgG1 subset) and IgM responses increased significantly across all vaccination groups after the first vaccination. Individual IgG subsets titres peaked significantly with all vaccines used after the second vaccination at week 5 and remained significant at week 12 when compared to week 0 . The toxin neutralization (TNA) titres of the NLAV vaccinated cattle groups showed similar trends to those observed with the ELISA titres, except that the former were lower, but still significant, when compared to week 0 . The opsonophagocytic assay indicated good antibody opsonizing responses with 75\% (PrPA+FIS), 66\% (CrPA+FIS) and 80\% (SLSV) phagocytosis following spores opsonization. In the passive protection test, A/J mice transfused with purified IgG from cattle vaccinated with PrPA+FIS+Emulsigen-D ${ }^{\circledR} /$ Alhydrogel ${ }^{\circledR}$ and SLSV had $73 \%$ and $75 \%$ protection from challenge with $B$. anthracis strain $34 \mathrm{~F} 2$ spores, respectively, whereas IgG from cattle vaccinated with CrPA+FIS+Emulsigen-D ${ }^{\circledR} /$ Alhydrogel ${ }^{\circledR}$ offered insignificant protection of $20 \%$. There was no difference in protective immune response in cattle vaccinated twice with either the PrPA+FIS or SLSV. Moreover, PrPA+FIS did not show any residual side effects in vaccinated cattle. These results suggest that the immunogenicity and protective efficacy induced by the NLAV (PrPA+FIS) in the cattle and passive mouse protection test, respectively, are comparable to that induced by the standard SLSV.
\end{abstract}

Keywords: anthrax; non-living; vaccine; immunogenicity; cattle 


\section{Introduction}

Anthrax is caused by the Gram-positive bacterium Bacillus anthracis known to primarily infect ruminants as well as other warm-blooded mammals [1]. It takes $3-5$ days of incubation in the ruminant host for the disease to progress to a peracute or acute course [2]. The B. anthracis bacilli are responsible for systemic toxaemia and bacteraemia via its main virulence factors [3], which are encoded by two extrachromosomal plasmids, namely pXO1 and pXO2 [4]. The pXO2 encodes poly- $\gamma$-D-glutamic acid capsule (PDGA), which is poorly immunogenic and prevents $B$. anthracis phagocytosis by evading immune surveillance during the early stage of anthrax infection [5]. The aforementioned process gives the vegetative forms of the bacteria leverage to produce the tripartite toxin proteins comprising the lethal factor (LF), oedema factor (EF) and protective antigen (PA), which are encoded by the plasmid pXO1. Individually, these proteins are nontoxic until united in the binary fusion with PA as the common binding moiety, and LF and EF as the catalytic moieties. PA combines with LF and EF individually to form the binary toxins, namely lethal toxin (LT) and oedema toxin (ET), respectively. PA facilitates the translocation of LF and EF into the cells where these toxins exert deleterious effects [6-8].

Anthrax epidemics are best controlled through vaccination [9]. The Sterne live spore vaccine (SLSV) consisting of attenuated B. anthracis 34F2 strain (lacking the pXO2 plasmid) is used for vaccinating animals in most countries. The vaccine strain was developed by Max Sterne in the 1930s by attenuating the $B$. anthracis strain isolated from a case of bovine anthrax [10]. Since its development, SLSV has proved to be effective in protecting vaccinated animals. Booster immunization with SLSV ensures hyper immunity in goats and an early booster vaccination (within 3 months) following the first immunization has been suggested [11]. Nonetheless, SLSV is not devoid of some drawbacks, which include residual virulence in livestock and laboratory animals, adverse reaction in some animal species following vaccination and incompatibility with concurrent antibiotic treatment in disease outbreak situations [10,12-15]. The development of a vaccine that can be administered concurrently with an antibiotic in the case of disease outbreak [16], the protection of valuable wildlife or for feedlots when moving animals with unknown immune status from different locations, which require prophylactic treatment and vaccination against prevalent diseases, will be of huge benefit to the domestic/wild livestock industry. Various studies have evaluated the recombinant rPA anthrax vaccine candidate in combination with other non-living $B$. anthracis vaccine candidates in laboratory animals [3,17-24]. Recently, goats were vaccinated thrice with non-living anthrax vaccine (NLAV) candidates comprising rPA, Bacillus collagen-like protein of anthracis (BclA) and formalin inactivated B. anthracis $34 \mathrm{~F} 2$ spores (FIS) (three-step vaccination schedule), and the findings showed that rPA and FIS stimulate better immune responses compared to BclA and that a two-step vaccination schedule may be sufficient $[16,25]$.

In this study, rPA (crude and purified) and FIS were adjuvanted with Emulsigen-D ${ }^{\circledR} /$ Alhydrogel $^{\circledR}$. Emulsigen- ${ }^{\circledR}$ is a unique emulsion (oil-in-water) containing dimethyl-dioctadecyl ammonium bromide (DDA), which is a good stimulator of T-cell immunity and increases the antigen surface area as well as the slow release of the antigen [26-28]. Alhydrogel ${ }^{\circledR}$ adjuvant is made up of aluminium hydroxide wet gel suspension. Alhydrogel ${ }^{\circledR}$ improves the uptake of antigens by antigen-presenting cells (APCs), induces NLRP3 inflammasome complexes as well as interleukin-1 (IL-1) and interleukin-18 (IL-18) secretion and increases Th2 antibodies response [29-31]. In a two-step vaccination schedule, vaccine candidates were administered to cattle and the immune response and protective efficacy of the antibody-based immune responses were determined. The immune responses induced by either purified and crude rPA combined with the FIS and adjuvants were compared to the immune responses induced in SLSV-vaccinated cattle. Specific immune responses were confirmed using ELISA, in vitro toxin neutralization assay (TNA) and opsonophagocytic assay. The protective efficacy was determined using a passive mouse protection test with purified antibodies from vaccinated cattle and lethal challenge with $B$. anthracis $34 \mathrm{~F} 2$ spores. 


\section{Results}

\subsection{Humoral Immune Response of Living and Non-Living Anthrax Vaccines in Cattle}

The immunogenicity of the non-living vaccines was compared with SLSV. Sera from the animals were tested for IgG and IgM against PA and FIS, lethal toxin neutralization as well as for immunoglobin subclasses, IgG1 and IgG2. The opsonophagocytosis of induced antibodies were also investigated.

Mean IgG titres against rPA rose significantly at week 3 for CrPA+FIS+Emulsigen-D ${ }^{\circledR} /$ Alhydrogel ${ }^{\circledR}$, PrPA+FIS+Emulsigen-D ${ }^{\circledR} /$ Alhydrogel $^{\circledR}$ and SLSV. The anti-rPA IgG titres were significantly higher for CrPA+FIS+Emulsigen-D ${ }^{\circledR} /$ Alhydroge $l^{\circledR}$ and PrPA+FIS+Emulsigen-D ${ }^{\circledR} /$ Alhydrogel ${ }^{\circledR}$ at week 5 (two weeks after the second vaccination) and week 12 when compared to the titres before vaccination (Figure 1). Similarly, the mean IgG titres against FIS increased significantly from week 3 for CrPA+FIS+Emulsigen-D ${ }^{\circledR} /$ Alhydrogel ${ }^{\circledR}$ and PrPA+FIS+Emulsigen-D ${ }^{\circledR} /$ Alhydrogel ${ }^{\circledR}$ but the anti-FIS IgG titres' increase were insignificant for SLSV. At week 5 (two weeks after the second vaccination), the mean IgG titres against FIS increased was highly significantly for CrPA+FIS+Emulsigen-D ${ }^{\circledR} /$ Alhydrogel ${ }^{\circledR}$ and PrPA+FIS+Emulsigen-D ${ }^{\circledR} /$ Alhydrogel ${ }^{\circledR}$ and remained significant at week 12 (Figure 2).

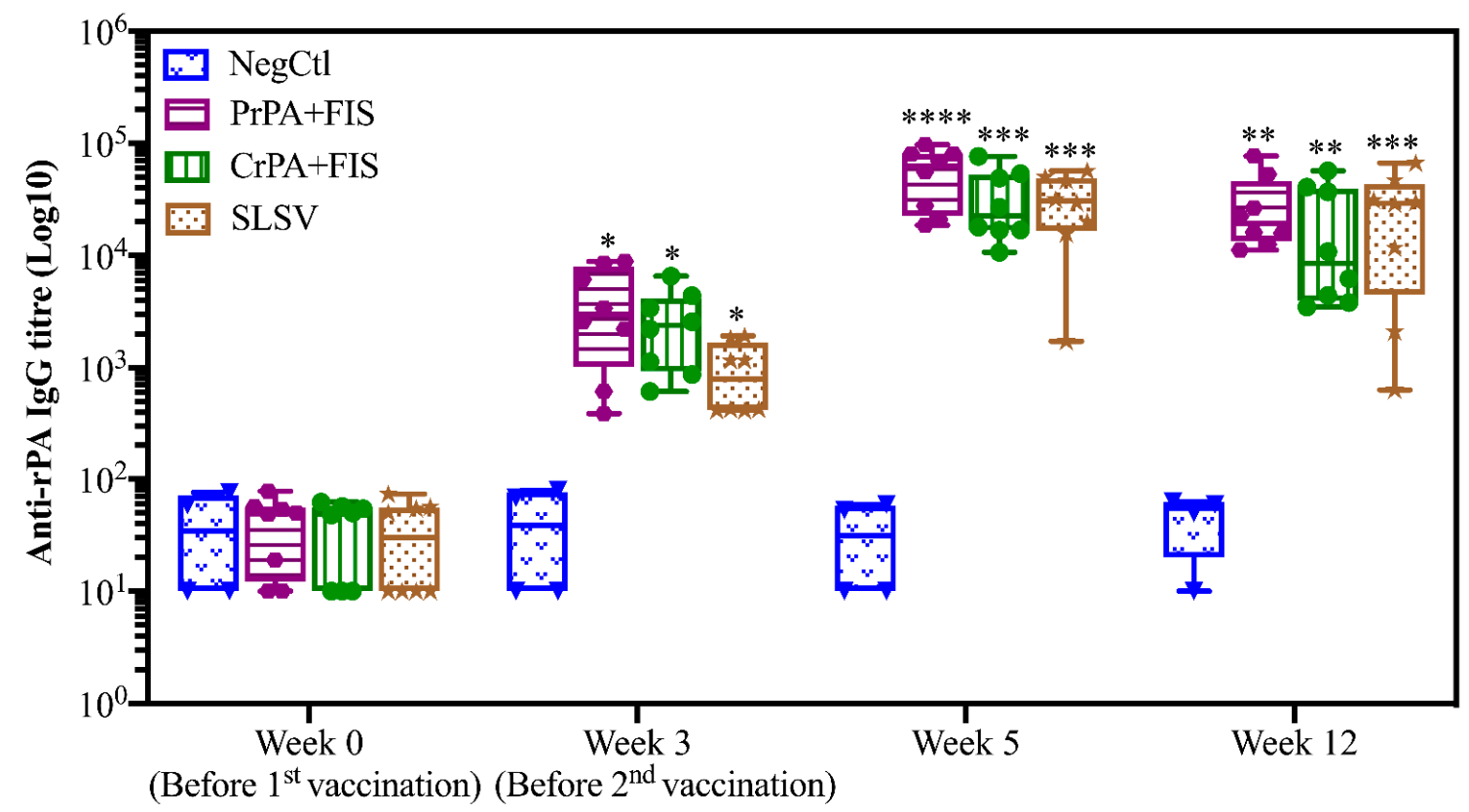

Different time points

Figure 1. Anti-recombinant protective antigen (rPA) IgG-titres in vaccinated cattle presented as box and whisker plots. The cattle were vaccinated twice at week 0 and 3 with PrPA+FIS+Emulsigen-D ${ }^{\circledR} /$ Alhydrogel ${ }^{\circledR}$ adjuvants $(n=8), C r P A+F I S+E m u l s i g e n-D^{\circledR} /$ Alhydrogel ${ }^{\circledR}$ adjuvants $(n=8)$, Sterne live spore vaccine (SLSV) $(n=8)$ and NegCtl (Emulsigen-D ${ }^{\circledR} /$ Alhydrogel ${ }^{\circledR}$ adjuvants) ( $n=4)$ with sera collected before the vaccinations at week 0 and 3 as well as samples collected at week 5 and 12. Sera dilution started at a concentration of 1:100 and values $<50$ were given an arbitrary value of 10 . IgG titres in each vaccinated group were compared to the respective pre-immune titres. The significant values between groups are presented as ${ }^{* * *} p<0.0001,{ }^{* * *} p<0.001$, ** $p<0.01$ and $* p \leq 0.05$. PrPA: Purified recombinant protective antigen, CrPA: Crude recombinant protective antigen FIS: Formalin inactivated spores, SLSV: Sterne live spore vaccine, NegCtl: Negative control vaccinated with Emulsigen-D ${ }^{\circledR} /$ Alhydrogel ${ }^{\circledR}$ adjuvants. 


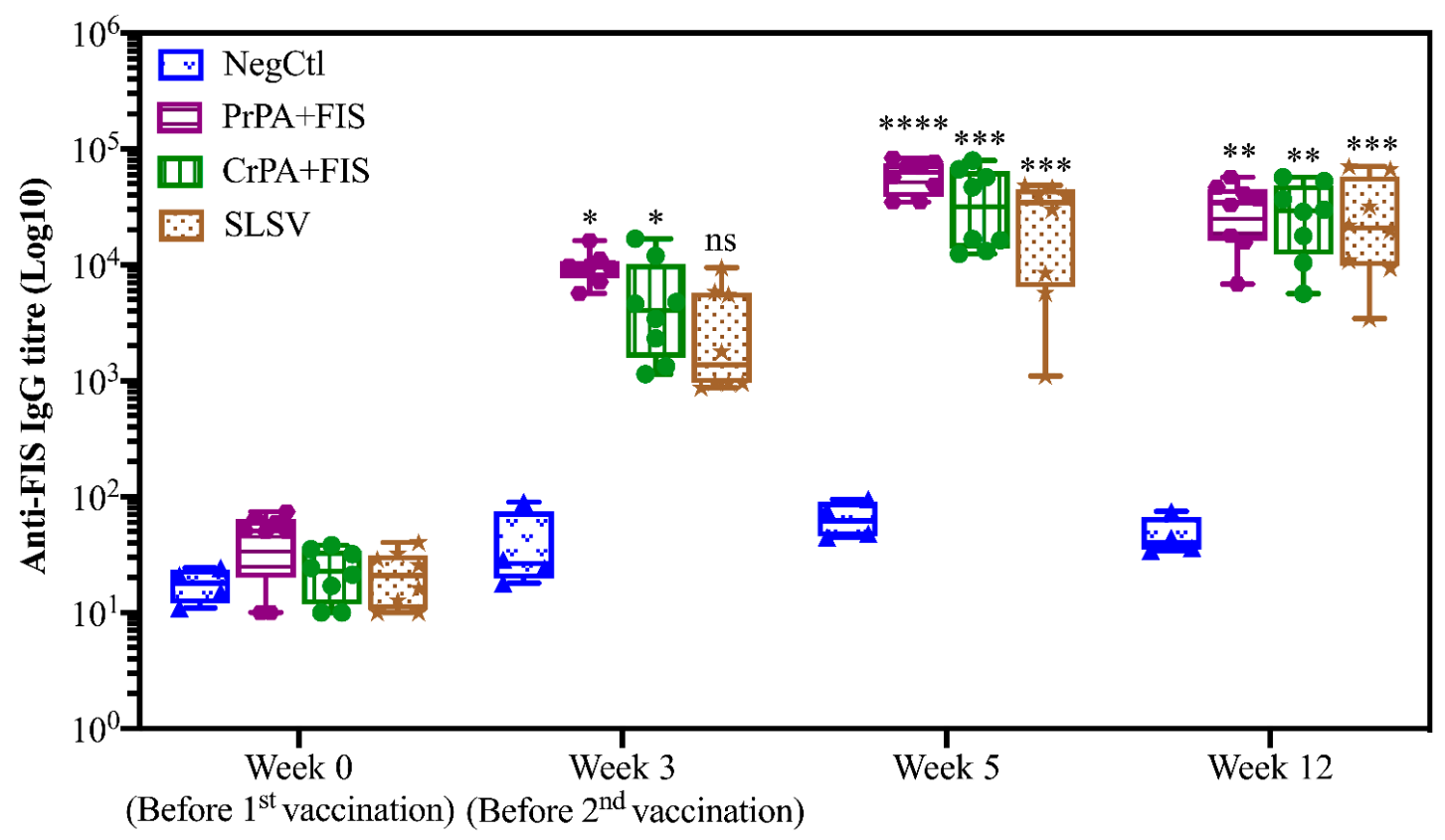

Different time points

Figure 2. Anti-FIS IgG-titres in vaccinated cattle presented as box and whisker plots. The cattle were vaccinated twice at week 0 and 3 with PrPA+FIS+Emulsigen-D ${ }^{\circledR} /$ Alhydrogel $^{\circledR}$ adjuvants $(\mathrm{n}=8), \mathrm{CrPA}+\mathrm{FIS}+$ Emulsigen-D ${ }^{\circledR} /$ Alhydrogel $^{\circledR}$ adjuvants $(\mathrm{n}=8), \mathrm{SLSV}(\mathrm{n}=8)$ and NegCtl (Emulsigen-D ${ }^{\circledR} /$ Alhydrogel ${ }^{\circledR}$ adjuvants) $(n=4)$ with sera collected before the vaccinations at week 0 and 3 as well as samples collected at week 5 and 12. Sera dilution started at a concentration of 1:100 and values $<50$ were given an arbitrary value of 10 . IgG titres in each vaccinated group were compared to the pre-immune titres. The significant values between groups are presented as ${ }^{* * *} p<0.0001,{ }^{* * *} p<0.001$, ${ }^{* *} p<0.01,{ }^{*} p \leq 0.05$. PrPA: Purified recombinant protective antigen, CrPA: Crude recombinant protective antigen FIS: Formalin inactivated spores, SLSV: Sterne live spore vaccine, NegCtl: Negative control vaccinated with Emulsigen-D ${ }^{\circledR} /$ Alhydrogel ${ }^{\circledR}$ adjuvants.

\subsection{Immunoglobulins IgM and IgG Subclasses Titres}

The antibody subclasses' responses against rPA in vaccinated cattle groups after the first and second vaccination are presented in Figure $3 \mathrm{a}-\mathrm{c}$. The anti-rPA IgM titres exhibited significant elevation against PrPA+FIS+Emulsigen-D ${ }^{\circledR} /$ Alhydroge $^{\circledR}, \mathrm{CrPA}+\mathrm{FIS}+$ Emulsigen-D ${ }^{\circledR} /$ Alhydrogel ${ }^{\circledR}$ and SLSV after the first and second vaccination, before decreasing at week 12 . The IgM titres at week 12 were still significant for PrPA+FIS+Emulsigen-D ${ }^{\circledR} /$ Alhydroge $^{\circledR}$ but not significantly higher for the +FIS+Emulsigen-D ${ }^{\circledR} /$ Alhydrogel ${ }^{\circledR}$ and SLSV group when compared to week 0. Thus, the group vaccinated with PrPA+FIS+Emulsigen-D $\mathrm{D}^{\circledR} /$ Alhydroge $^{\circledR}{ }^{\circledR}$ still had significantly higher titres, despite the decline in the IgM levels (Figure 3a). The anti-rPA IgG1 titres also showed a significant increase for PrPA+FIS+Emulsigen-D ${ }^{\circledR} /$ Alhydrogel ${ }^{\circledR}$, CrPA+FIS+Emulsigen-D ${ }^{\circledR} /$ Alhydrogel ${ }^{\circledR}$, and SLSV at week 3 and, at week 5, the anti-rPA IgG1 titres for PrPA+FIS+Emulsigen-D ${ }^{\circledR} /$ Alhydrogel ${ }^{\circledR}$, CrPA+FIS+Emulsigen-D ${ }^{\circledR} /$ Alhydrogel ${ }^{\circledR}$, and SLSV increase were highly significant. However, the anti-rPA IgG1 titres declined below significance at week 12 for PrPA+FIS+Emulsigen-D ${ }^{\circledR} /$ Alhydrogel $^{\circledR}$, CrPA+FIS+Emulsigen-D ${ }^{\circledR} /$ Alhydrogel ${ }^{\circledR}$ and SLSV (Figure 3b). The anti-rPA IgG2 titres at week 3 were not different from the pre-vaccination titres for all the vaccine groups. However, analysis at week 5 and 12 showed highly significant increases for anti-rPA IgG2 titres in all vaccine (Figure 3c). 


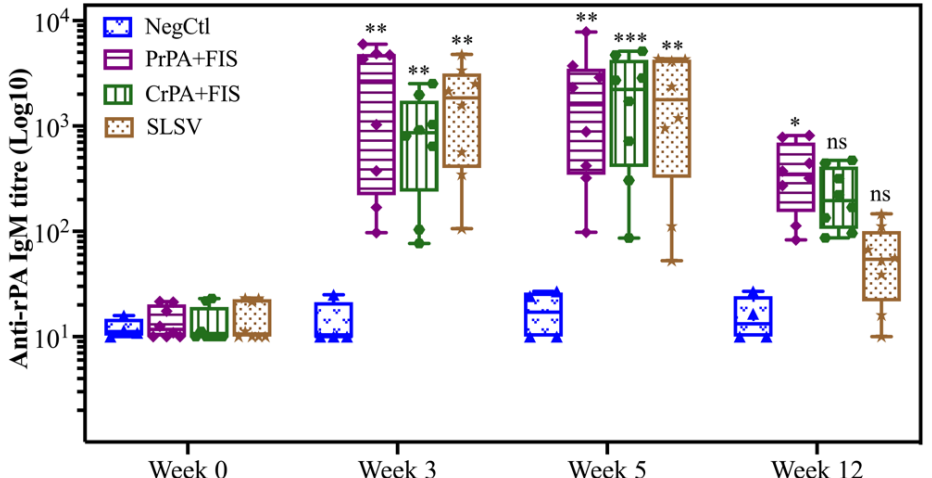

$$
\text { Week } 0
$$$$
\text { Week } 3
$$

Week 5

Week 12

Different time points

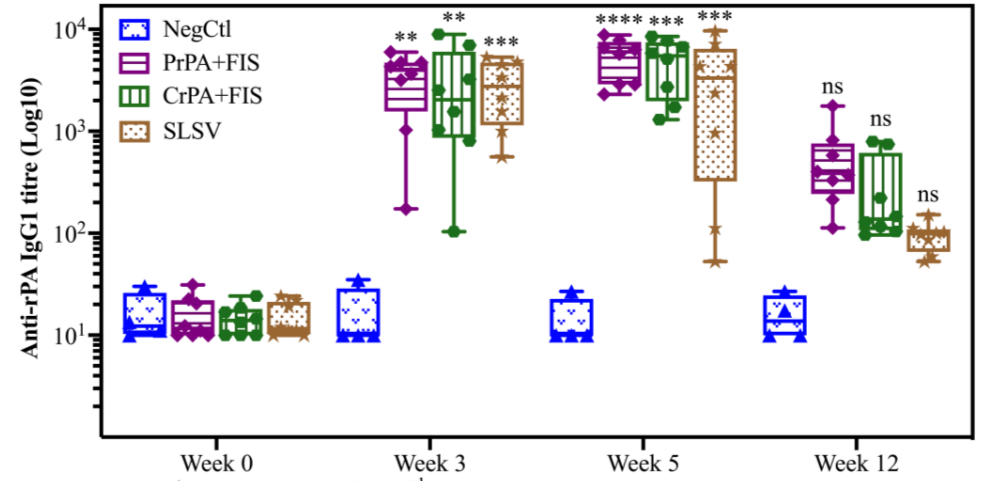

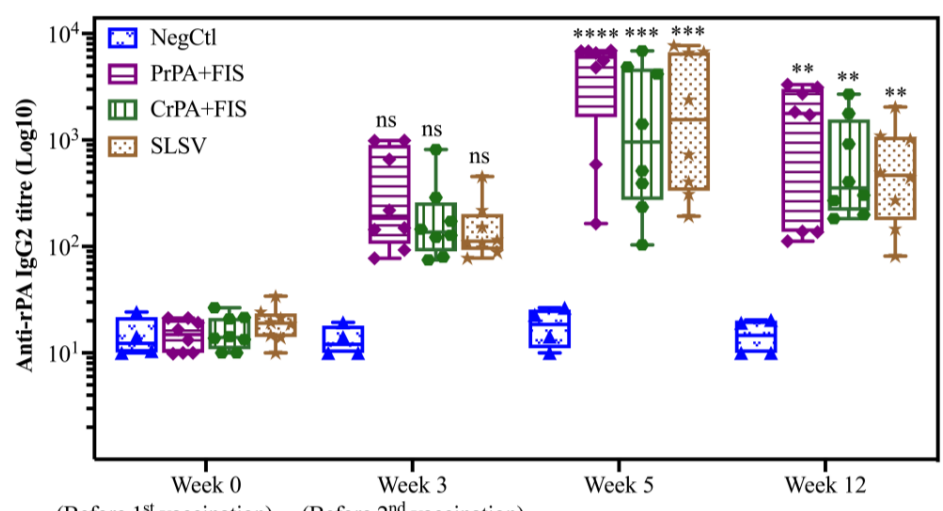

(c) $\begin{array}{rr}\text { (Before } 1^{\text {st }} \text { vaccination) } & \text { (Before } 2^{\text {nd }} \text { vaccination) } \\ \text { Different time points }\end{array}$

Figure 3. The anti-rPA IgM and IgG subclasses (IgG1 and IgG2) ELISA titres of cattle are vaccinated at week 0 and 3 with either PrPA+FIS+Emulsigen-D ${ }^{\circledR} / A l h y d r o g e l^{\circledR}$ adjuvants $(n=8)$, CrPA+FIS+Emulsigen-D ${ }^{\circledR} /$ Alhydrogel ${ }^{\circledR}$ adjuvants $(n=8)$, SLSV $(n=8)$ and Emulsigen-D ${ }^{\circledR} /$ Alhydrogel ${ }^{\circledR}$ adjuvants $($ NegCtl $)(n=4)$ are presented as box and whisker plots. The cattle sera samples were collected before the vaccinations at week 0 and 3 as well as at week 5 and 12 . Sera dilution started at a concentration of 1:50 and values below the $(<50)$ were given an arbitrary value of 10 . (a): Anti-rPA IgM ELISA titres, (b): Anti-rPA IgG1 ELISA titres and (c): Anti-rPA IgG2 ELISA titres. The significant values were presented as ${ }^{* * *} p<0.0001,{ }^{* * *} p<0.001,{ }^{* *} p<0.01,{ }^{*} p \leq 0.05$, ns $=$ not significant. PrPA: Purified recombinant protective antigen, CrPA: Crude recombinant protective antigen FIS: Formalin inactivated spores, SLSV: Sterne live spore vaccine, NegCtl: Negative control vaccinated with Emulsigen-D ${ }^{\circledR} /$ Alhydrogel ${ }^{\circledR}$ adjuvants. 
The anti-FIS IgM and IgG subclasses response in vaccinated cattle groups after the first and the second vaccination are shown in Figure $4 \mathrm{a}-\mathrm{c}$. The anti-FIS IgM titres after the first vaccination showed a significant increase for PrPA+FIS+Emulsigen-D ${ }^{\circledR} /$ Alhydrogel ${ }^{\circledR}$, CrPA+FIS+Emulsigen-D ${ }^{\circledR} /$ Alhydrogel ${ }^{\circledR}$, and SLSV. The increase in IgM titres at week 5 after the second vaccination for PrPA+FIS+Emulsigen- $\mathrm{D}^{\circledR} /$ Alhydroge ${ }^{\circledR}, \mathrm{CrPA}+\mathrm{FIS}+$ Emulsigen-D ${ }^{\circledR} /$ Alhydrogel ${ }^{\circledR}$ and SLSV were highly significant, however these were insignificant at week 12 across all the vaccine groups when compared to week 0 (Figure $4 \mathrm{a}$ ). The mean anti-FIS IgG1 titres also showed a significant increase for $\operatorname{PrPA}+F I S+E m u l s i g e n-D^{\circledR} /$ Alhydroge $^{\circledR}$, SLSV and CrPA+FIS+Emulsigen-D ${ }^{\circledR} /$ Alhydrogel $^{\circledR}$ at week 3 and retained significance at week 5 across all vaccine groups. The anti-FIS IgG1 mean titres level decreased but were still significant at week 12 for SLSV and PrPA+FIS+Emulsigen- $\mathrm{D}^{\circledR} /$ Alhydrogel ${ }^{\circledR}$ but not significant for CrPA+FIS+Emulsigen-D ${ }^{\circledR} /$ Alhydrogel ${ }^{\circledR}$ (Figure $4 \mathrm{~b}$ ). The anti-FIS IgG2 mean titres' increases were significant for PrPA+FIS+Emulsigen-D $\mathrm{D}^{\circledR} /$ Alhydrogel ${ }^{\circledR}, \mathrm{CrPA}+\mathrm{FIS}+$ Emulsigen-D $\mathrm{D}^{\circledR} /$ Alhydroge $^{\circledR}$ and SLSV at week 3, increased further at week 5 for PrPA+FIS+Emulsigen-D ${ }^{\circledR} /$ Alhydrogel $^{\circledR}$ and SLSV, while declining (but still significantly higher than pre-vaccination titres) for CrPA+FIS+Emulsigen-D ${ }^{\circledR} /$ Alhydroge ${ }^{\circledR}$. At week 12, the anti-FIS IgG2 mean titres were significant for PrPA+FIS+Emulsigen-D ${ }^{\circledR} /$ Alhydrogel ${ }^{\circledR}$, CrPA+FIS+Emulsigen-D ${ }^{\circledR} /$ Alhydroge ${ }^{\circledR}$ and SLSV (Figure 4c). The immunoglobulins subclasses mean titres against rPA and FIS of NegCtl group consisting of cattle vaccinated with adjuvants did not change significantly across all the timepoints when compared to the titres at week 0 . 


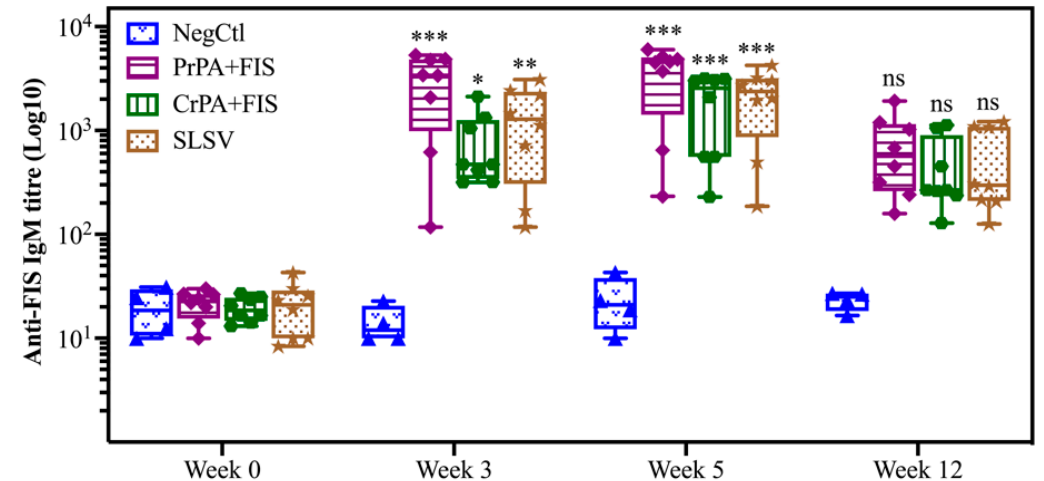

(a) (Before $1^{\text {st }}$ Vaccination) (Before $2^{\text {nd }}$ Vaccination) Different time points

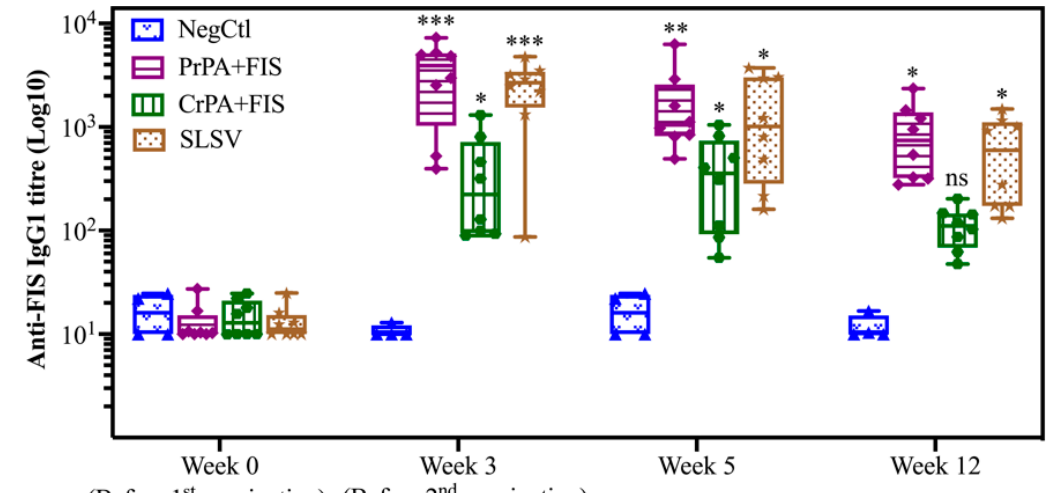

(b)

Different time points

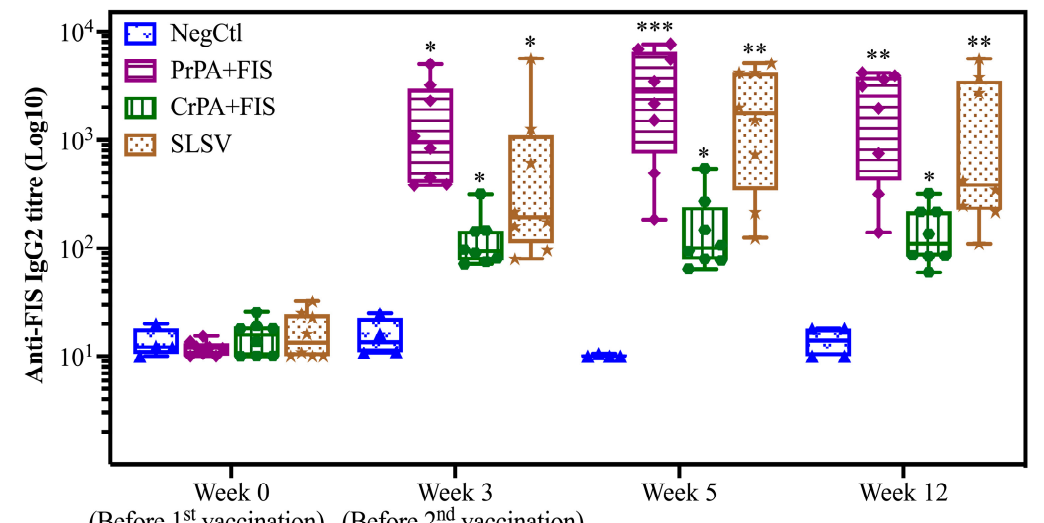

Different time points

Figure 4. The anti-FIS IgM and IgG subclasses (IgG1 and IgG2) ELISA titres of cattle are vaccinated at week 0 and 3 with either PrPA+FIS+Emulsigen-D ${ }^{\circledR} / A l h y d r o g e l{ }^{\circledR}$ adjuvants $(n=8)$, CrPA+FIS+Emulsigen-D ${ }^{\circledR} /$ Alhydrogel ${ }^{\circledR}$ adjuvants $(n=8)$, SLSV $(n=8)$ and Emulsigen-D ${ }^{\circledR} /$ Alhydrogel ${ }^{\circledR}$ adjuvants $($ NegCtl $)(n=4)$ are presented as box and whisker plots. The cattle sera samples were collected before the vaccinations at week 0 and 3 as well as at week 5 and 12 . Sera dilution started at a concentration of 1:50 and values below the $(<50)$ were given an arbitrary value of 10. (a): Anti-FIS IgM ELISA titres, (b): Anti-FIS IgG1 ELISA titres and (c): Anti-FIS IgG2 ELISA titres. The significant values were presented as ${ }^{* * * *} p<0.0001,{ }^{* * *} p<0.001,{ }^{* *} p<0.01,{ }^{*} p \leq 0.05$, ns $=$ not significant. PrPA: Purified recombinant protective antigen, CrPA: Crude recombinant protective antigen FIS: Formalin inactivated spores, SLSV: Sterne live spore vaccine, NegCtl: Negative control vaccinated with Emulsigen-D ${ }^{\circledR} /$ Alhydrogel $^{\circledR}$ adjuvants. 
The lethal toxin neutralizing antibodies $\left(\mathrm{NT}_{50}\right)$ titres of cattle vaccinated with NLAV, SLSV and adjuvant $(\mathrm{NegCtl})$ are shown in Figure 5. The lethal toxin neutralizing antibody titres increased (though not significantly) across all vaccination groups after the first vaccination at week 3 . The $\mathrm{NT}_{50}$ titres for all vaccine groups increased significantly at week 5 and 12 when compared to pre-vaccination titres. (Figure 5). The $\mathrm{NT}_{50}$ remained below the detection limit among the NegCtl throughout the period of study.

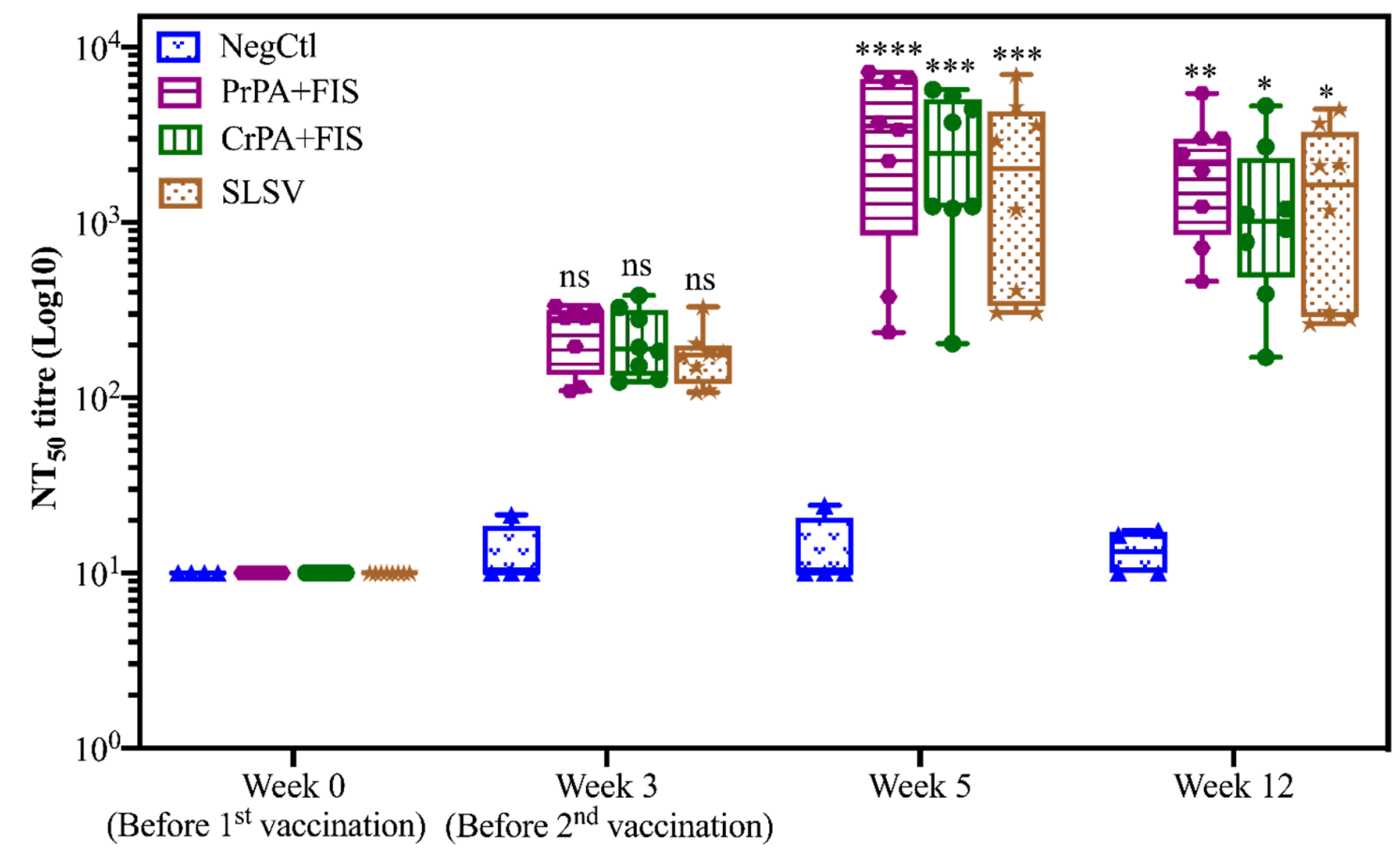

Different time points

Figure 5. Lethal toxin neutralizing titres in vaccinated cattle. The cattle were vaccinated twice at week 0 and 3 with PrPA+FIS+Emulsigen-D ${ }^{\circledR} /$ Alhydrogel $^{\circledR}$ adjuvants $(n=8)$, CrPA+FIS+Emulsigen-D ${ }^{\circledR} /$ Alhydrogel $^{\circledR}$ adjuvants $(n=8), \quad$ SLSV $\quad(n=8)$ and NegCtl (Emulsigen-D ${ }^{\circledR} /$ Alhydrogel ${ }^{\circledR}$ adjuvants) $(n=4)$ with sera collected before the vaccinations at week 0 and 3 as well as at week 5 and 12. Sera with no detectable toxin-neutralizing titres were given an arbitrary value of 10 and sera dilution started at a concentration of 1:50. Neutralizing titres in each vaccinated group were compared to the respective pre-immune titres. The significant values between groups are presented as ${ }^{* * *} p<0.0001,{ }^{* * *} p<0.001,{ }^{* *} p<0.01,{ }^{*} p \leq 0.0 .5$, ns $=$ not significant. PrPA: Purified recombinant protective antigen, CrPA: Crude recombinant protective antigen FIS: Formalin inactivated spores, SLSV: Sterne live spore vaccine, NegCtl: Negative control vaccinated with Emulsigen-D ${ }^{\circledR} /$ Alhydrogel $^{\circledR}$ adjuvants.

\subsection{Opsonising Ability of Vaccine-Induced Antibodies}

Sera collected at week 5 from cattle vaccinated with NLAV and SLSV were used to determine the potential of induced antibodies to opsonize $B$. anthracis spores, thereby enabling spores' phagocytosis by RAW 264.7 macrophage (Figure 6). The macrophages showed a high level of spore uptake at 1:10 sera dilution for both SLSV and NLAV vaccine groups. The RAW 264.7 macrophages showed $80 \%, 75 \%$ and $66 \%$ spore uptake following treatment with immune sera from SLSV, PrPA+FIS+Emulsigen-D ${ }^{\circledR} /$ Alhydrogel ${ }^{\circledR}$ and CrPA+FIS+Emulsigen- $D^{\circledR} /$ Alhydrogel ${ }^{\circledR}$ vaccine groups, respectively. The NegCtl showed the least level of macrophage spore uptake (17\%) following incubation with sera (Figure 6). The spore uptake at 1:100, 1:1000 and 1:10000 dilutions of sera from the SLSV and PrPA+FIS+Emulsigen-D ${ }^{\circledR} /$ Alhydrogel ${ }^{\circledR}$ vaccine groups in the opsonophagocytosis assay remained significantly high when compared to the negative control sera (Figure 6). Sera from 
CrPA+FIS+Emulsigen-D ${ }^{\circledR} /$ Alhydrogel ${ }^{\circledR}$ did not show a significant macrophage spore uptake at dilutions above 1:100.

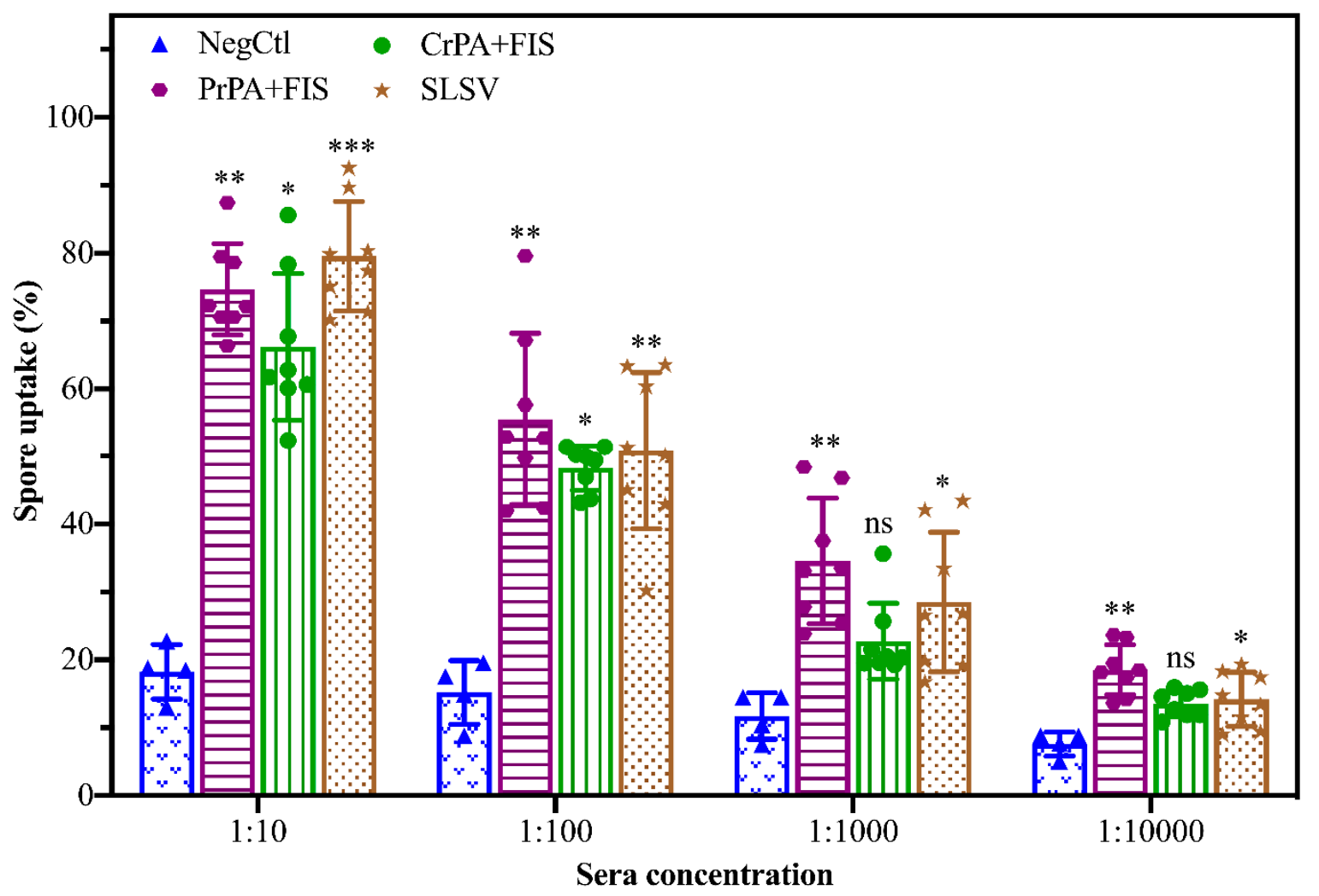

Figure 6. Bacillus anthracis 34F2 spores' uptake (phagocytosis) by RAW 267.7 macrophages following incubation with varying dilutions of sera from vaccinated and negative control groups. The mean value of spore uptake is presented in the form of bar charts with the three standard deviations. The level of opsonophagocytosis of each group at every dilution was compared to the negative control (NegCtl) of each dilution. The significant values were presented as, ${ }^{* * *} p<0.001,{ }^{* *} p<0.01,{ }^{*} p \leq 0.05$, ns = not significant. PrPA: Purified recombinant protective antigen, CrPA: Crude recombinant protective antigen FIS: Formalin inactivated spores, SLSV: Sterne live spore vaccine, NegCtl: Negative control vaccinated with Emulsigen-D ${ }^{\circledR} /$ Alhydroge ${ }^{\circledR}$ adjuvants.

\subsection{Protection Conferred on A/J Mice by Antibodies from Cattle Immune Sera}

The ability of the polyclonal IgG purified from cattle vaccinated with NLAV and SLSV to protect $\mathrm{A} / \mathrm{J}$ mice from challenge with toxigenic $B$. anthracis $34 \mathrm{~F} 2$ strain spores was determined using a passive mouse protection model. The NegCtl group consisting of mice with antibodies from cattle vaccinated, with the adjuvants only died 3-7 days following the challenge (Figure 7). A significant level of protection was seen among groups of $\mathrm{A} / \mathrm{J}$ mice that were transfused with antibodies from PrPA+FIS+Emulsigen- $\mathrm{D}^{\circledR} /$ Alhydrogel ${ }^{\circledR}$ and SLSV-vaccinated cattle recorded $73 \%$ and $75 \% \mathrm{~A} / \mathrm{J}$ mice protection. However, IgG from CrPA+FIS+Emulsigen-D ${ }^{\circledR} /$ Alhydrogel ${ }^{\circledR}$ vaccinated cattle were unable to confer significant protection to the $\mathrm{A} / \mathrm{J}$ mice, with only $20 \%$ of the $\mathrm{A} / \mathrm{J}$ mice protected from the lethal effect of $B$. anthracis $34 \mathrm{~F} 2$ strain spores. 


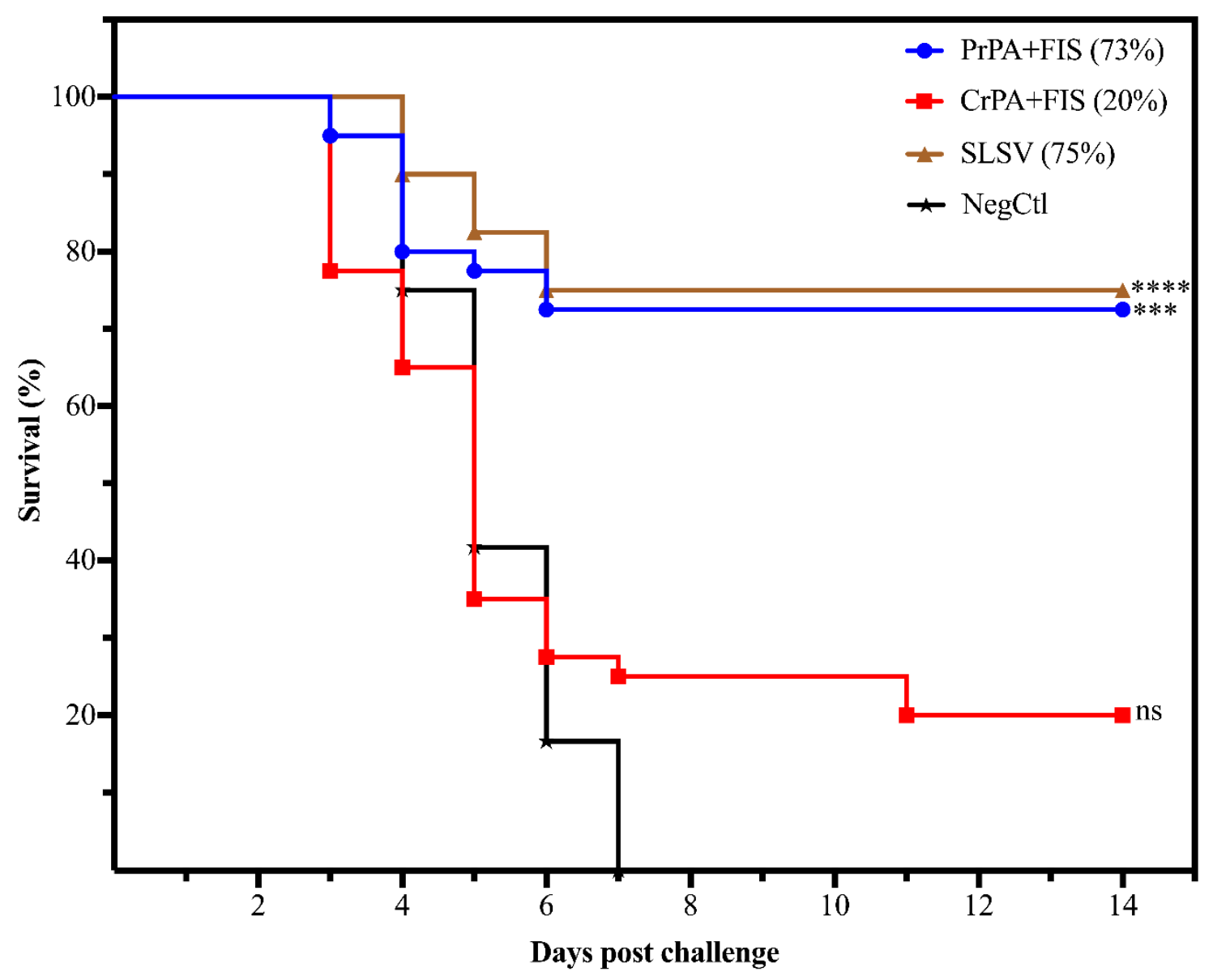

Figure 7. The cumulative mice survival curve following passive in vivo transfer of polyclonal $\operatorname{IgG}$ purified from cattle immune sera A/J mice. The mice were lethally challenged with $2.16 \times 10^{5} \mathrm{~B}$. anthracis 34F2 spores. The sera are from cattle vaccinated twice (week 0 and 3) with either PrPA+FIS, CrPA+FIS, SLSV groups adjuvanted with emulsigen- $D^{\circledR} /$ alhydrogel ${ }^{\circledR}$ and a NegCtl group (also see Table 2 for the number of mice allocated to each group). The survival rate in the Log-rank (Mantel-Cox) test was compared to the NegCtl group. The significant values between groups are presented as ${ }^{* * * *} p<0.0001,{ }^{* * *} p<0.001$, ns $=$ not significant. PrPA: Purified recombinant protective antigen, CrPA: Crude recombinant protective antigen, FIS: Formalin inactivated spores, NegCtl: Negative control vaccinated with Emulsigen-D ${ }^{\circledR} /$ Alhydroge ${ }^{\circledR}$ adjuvants.

Furthermore, we evaluated the relationship between the humoral and neutralizing antibody titres from the vaccine groups and the level of protection conferred to $\mathrm{A} / \mathrm{J}$ mice following lethal challenge. Our findings revealed there is a correlation between anti-rPA, anti-FIS and $\mathrm{NT}_{50}$ antibody titres from the group vaccinated with PrPA+FIS+Emulsigen-D ${ }^{\circledR} /$ Alhydrogel ${ }^{\circledR}$ and SLSV and the rate of survival in passively challenged A/J mice (Table 1). However, there was no correlation between the survival rate of the passively challenged $\mathrm{A} / \mathrm{J}$ mice and the anti-rPA, anti-FIS and $\mathrm{NT}_{50}$ antibody titres from the CrPA+FIS+Emulsigen-D ${ }^{\circledR} /$ Alhydroge $l^{\circledR}$ vaccinated group. 
Table 1. The correlation between antibody titres in sera from vaccinated cattle and survival time to death of challenged mice after passive transfer of purified antibodies.

\begin{tabular}{cccccccccc}
\hline & $\begin{array}{c}\text { Anti-rPA } \\
\text { (PrPA+FIS) }\end{array}$ & $\begin{array}{c}\text { Anti-rPA } \\
\text { (CrPA+FIS) }\end{array}$ & $\begin{array}{c}\text { Anti-rPA } \\
\text { (SLSV) }\end{array}$ & $\begin{array}{c}\text { Anti-FIS } \\
\text { (PrPA+FIS) }\end{array}$ & $\begin{array}{c}\text { Anti-FIS } \\
\text { (CrPA+FIS) }\end{array}$ & $\begin{array}{c}\text { Anti-FIS } \\
\text { (SLSV) }\end{array}$ & $\begin{array}{c}\text { TNA } \\
\text { (PrPA+FIS) }\end{array}$ & $\begin{array}{c}\text { TNA } \\
\text { (CrPA+FIS) }\end{array}$ & $\begin{array}{c}\text { TNA } \\
\text { (SLSV) }\end{array}$ \\
\hline $\begin{array}{c}\text { Pearson } \\
\text { correlation }\end{array}$ & $0.8196^{*}$ & $0.1237^{\mathrm{ns}}$ & $0.9239^{* *}$ & $0.7883^{*}$ & $0.3836^{\mathrm{ns}}$ & $0.8518^{* *}$ & $0.8588^{* *}$ & $0.4564^{\mathrm{ns}}$ & $0.8778^{* *}$ \\
\hline $\begin{array}{c}\text { Significance } \\
\text { (2-tailed) }\end{array}$ & 0.0128 & 0.7704 & 0.0010 & 0.0201 & 0.3482 & 0.0073 & 0.0063 & 0.2556 & 0.0042 \\
\hline
\end{tabular}

PrPA: Purified recombinant protective antigen, CrPA: Crude recombinant protective antigen, FIS: Formalin inactivated spores, NegCtl: Negative control vaccinated with Emulsigen- $\mathrm{D}^{\circledR} /$ Alhydrogel ${ }^{\circledR}$ adjuvants. ${ }^{* *}$ Correlation significant: 0.001 (2-tailed), ${ }^{*}$ Correlation significant: 0.05 (2-tailed). ${ }^{\text {ns }}$ Correlation not significant: 0.1234 (2-tailed).

\section{Discussion}

SLSV, as a live spore vaccine, is effective in the control of anthrax in livestock globally and has been the vaccine of choice in veterinary practice since the initial largescale production immunization trials in the 1940s [10,32]. Despite the success achieved with the SLSV, several drawbacks, such as residual virulence in some vaccinated animals and contraindications in anthrax outbreak situations due to its incompatibility with antibiotics, remain $[13,14,33]$. NLAV can be used in these scenarios simultaneously with antibiotics without interference on the immunogenicity of the vaccine. Various components of B. anthracis, such as PA, BclA, BxpB, LF and EF as well as the inactivated form of the whole B. anthracis spore, have been exhaustively studied alone or in combination for immunogenicity $[3,12,16,17,25,34-40]$. Among them, PA stands out as the major immunogenic component with the potential of stimulating toxin-neutralizing antibodies [41,42]. Other studies have reported an increase in immunogenicity and protection when PA is used in combination with other immunogenic components of $B$. anthracis or FIS $[16,17,19,20,23,25,39,40,43]$. Most of these studies were conducted in laboratory animals except the studies by [25] and [16] were conducted in goats. These studies [16,25] reported that combination of rPA and FIS provided a significant immune response in the three-step vaccination schedule in goats, as well as hypothesizing that a two-step vaccination schedule might provide sufficient protection based on the immune response observed in the goats. Therefore, in our study, cattle were vaccinated twice with NLAV (PrPA+FIS and CrPA+FIS) with Emulsigen-D ${ }^{\circledR} /$ Alhydrogel ${ }^{\circledR}$ and compared to the SLSV. The PrPA+FIS+Emulsigen-D ${ }^{\circledR} /$ Alhydroge ${ }^{\circledR}$ and CrPA+FIS+Emulsigen-D ${ }^{\circledR} /$ Alhydrogel ${ }^{\circledR}$ and SLSV vaccinated groups provided $73 \%, 20 \%$ and $75 \%$ protection, respectively, to mice that were passively immunized with purified cattle antibodies and challenged with toxigenic spores of B. anthracis. The negative control mice from cattle sera vaccinated twice with adjuvants only died within 7 days. Our results confirmed that a two-step vaccination schedule of PrPA+FIS+Emulsigen-D ${ }^{\circledR} /$ Alhydrogel ${ }^{\circledR}$ in cattle provide the same level of protection in the mouse protection assay as a two-step vaccination with SLSV. Ndumnego et al. [11] showed that two-step vaccine schedule (three months apart) of SLSV provided maximum protection to goats and also that the thrice vaccinated NLAV (consisting of a rPA+rBclA+FIS+lipopeptide adjuvant) can probably be reduced to a two-step vaccination schedule based on the immune response in goats $[11,16]$. A Pam ${ }_{3} \mathrm{Cys}_{-} \mathrm{SK}_{4}$ lipopeptide adjuvant known to enhance humoral immune response was used in these studies [44]. However, this was replaced in our study by the emulsigen- ${ }^{\circledR} /$ alhydrogel ${ }^{\circledR}$ adjuvants licensed to our industrial partner Design Biologix with similar results.

The immunoglobulin subclasses titres exhibited a balance between TH1 and TH2-type responses. Even though the TH2-type immune response dominates the response at week 5, as seen with IgG2 in both NLAV and SLSV against FIS, a similar trend is also seen with IgG1 and IgG2 response against rPA at the same timepoint, which signifies the stimulation of TH1-type response as well. The IgG1 titres declined, but were still significant at week 12, unlike IgG2, which maintained the trends of titres from week 5 at week 12 . However, the dynamics of the immune response switch between the immunoglobulin subclasses cannot be fully elucidated, as only four timepoints only are reported in the 12 weeks of this study. 
Solely PA-based vaccines were reported to be less protective against virulent challenge compared to the live spore vaccine $[17,20,45]$. The combination of PA and FIS in vaccine formulation conferred better protection [17]. Hence, the presence of FIS in our formulation may be associated with the level of protection in the passive mouse protection test. The anti-PA, anti-FIS IgG and TNA titres of cattle vaccinated with the purified rPA+FIS+Emulsigen-D ${ }^{\circledR} /$ Alhydrogel ${ }^{\circledR}$ correlated to the rate of protection achieved in the passive mouse protection test (Table 1). This is similar to the report by Ndumnego et al. [16], with a positive correlation between anti-PA, anti-FIS and TNA titres of vaccinated goats and protection observed in passive mouse protection test.

Interestingly, the rate of protection recorded in the cattle group vaccinated with CrPA+FIS+Emulsigen- $\mathrm{D}^{\circledR} /$ Alhydrogel $^{\circledR}$ did not correlate with the antibody titres obtained against rPA and FIS as well as to the $\mathrm{NT}_{50}$. Obviously, the purity of the rPA used in the PrPA+FIS+Emulsigen-D ${ }^{\circledR} /$ Alhydrogel ${ }^{\circledR}$ vaccine was of importance for the rate of survival recorded in the mouse trial. The CrPA+FIS+Emulsigen- $\mathrm{D}^{\circledR} / A$ lhydrogel ${ }^{\circledR}$ vaccine was included in this study as a lower-cost vaccine prototype, as opposed to the more expensive PrPA+FIS+Emulsigen-D ${ }^{\circledR} /$ Alhydrogel $^{\circledR}$ vaccine, which necessitates the purification of rPA by affinity chromatography. The low survival rate of mice after passive immunization with sera of CrPA+FIS+Emulsigen-D ${ }^{\circledR} /$ Alhydrogel ${ }^{\circledR}$ vaccinated cattle could be due to restricted access to B-cell epitopes in the crude rPA preparation. This may result in the blockage of the PA epitopes that are responsible for the inducement of protective antibodies, as previously reported by Crowe et al. [46]. Additionally, Crowe et al. [46] observed that peptide-specific antibodies against the furin cleavage, ligand-binding and receptor binding regions of PA are responsible for neutralization (in vitro) with the furin cleavage site mediating the best protection in vitro while displaying less protection in vivo. Antibodies against the receptor-binding site showed the most robust protection in vivo, despite displaying lower protection in vitro. Further work will be needed to confirm this. Moreover, the presence of the array of proteins in the CrPA+FIS+Emulsigen-D ${ }^{\circledR} /$ Alhydrogel ${ }^{\circledR}$ formulation may have stimulated non-specific antibody responses, adding to the overall titres measured in the whole-cell FIS ELISA [47]. In our study, we revealed that polyclonal antibodies from cattle vaccinated with PrPA+FIS+Emulsigen-D ${ }^{\circledR} /$ Alhydroge ${ }^{\circledR}, \mathrm{CrPA}+\mathrm{FIS}+$ Emulsigen-D $\mathrm{D}^{\circledR} /$ Alhydroge ${ }^{\circledR}$ and SLSV were able to opsonize and enable the uptake of $75 \%, 66 \%$ and $80 \%$ spores by macrophages. The opsonization of spores may substantially contribute to the rate of killing of phagocytosed spores by macrophages [37].

\section{Materials and Methods}

\subsection{Recombinant Protein Expression and Purification}

The construction of $\mathrm{PA}_{83}$ coupled to the His-tag expressing pStaby1.2 plasmid in Escherichia coli SE1 was done by Delphi Genetic, Belgium, using the PA83 primers and method, as described by Hahn et al (2004), and was designated pStaby1.2-PA83.1. The pStaby1.2-PA83.1 transformed into E. coli SE1 was expressed by culturing in Luria-Bertani (LB) broth medium at $25^{\circ} \mathrm{C}$ in a shaking incubator and observed until an optical density of 0.8 at $600 \mathrm{~nm}$ was reached. Then, protein expression was induced with $0.3 \mathrm{mM}$ of isopropyl-beta-D-thiogalactopyranoside (IPTG) and the E. coli SE1 were further incubated overnight at $25^{\circ} \mathrm{C}$ before harvesting by centrifuging at $2500 \mathrm{xg}$ for $35 \mathrm{~min}$. The pellet was washed with double distilled water. The protein was purified following the lysis of E. coli SE1 by suspending the pellet of the bacteria in a lysis buffer $\left(400 \mathrm{mmol} / \mathrm{l} \mathrm{NaCl}, 50 \mathrm{mmol} / \mathrm{l} \mathrm{NaH} \mathrm{H}_{2} \mathrm{PO}_{4}\right.$ and $20 \mathrm{mmol} / \mathrm{l} \mathrm{Tris;} \mathrm{pH} 7.85)$, followed by three freeze-thawing cycles of -20 and $4{ }^{\circ} \mathrm{C}$, respectively, in each cycle. The lysing process also included two cycles of sonication immediately after the freezing and thawing cycles. Each sonication cycle consisted of $20 \mathrm{~s}$ of sonication and $10 \mathrm{~s}$ without sonication on ice using a probe sonicator (BioLogics, Manassas, VA, USA) three times. Following sonification, the lysate was centrifuged at $2500 \times g$ for $35 \mathrm{~min}$ and the supernatant was collected. The supernatant was treated in two different ways to formulate crude and purified rPA. The crude rPA (CrPA) supernatant was treated with Limulus Amoebocyte Lysate (LAL) endosafe endotoxin quantification and removal kit 
(ThermoFisher Scientific Rockford, IL, USA). To prepare PrPA, the supernatant was purified using $\mathrm{Ni}^{2+}$-TED column (Machery-Nagel, Düren, Germany) as directed by the manufacturer, followed by filtration using an LAL endosafe endotoxin Quantification and removal kit (ThermoFisher Scientific). The rPA protein was confirmed by SDS PAGE and Western blot using 4-20\% protein gel (ThermoFisher Scientific), and the rPA protein yield was quantified with Pierce BCA protein assay kit (ThermoFisher Scientific) following the manufacturer's protocol. The purified protein procedure was followed for rPA83 used in the ELISA.

To determine the amount of PA in the crude vaccine, $1 \mathrm{~mL}$ of CrPA was purified with the $\mathrm{Ni}^{2}$-TED column and protein concentration was determined using the Pierce BCA protein assay kit (ThermoFisher Scientific) according to the manufacture's instruction. The results were used as a standard to calculate the concentration CrPA (Supplementary Material 1). The PrPA and CrPA concentrations were used in the vaccine formulation (see the section, "formulation of non-living anthrax vaccine", below).

\subsection{Formalin-Inactivated Spores (FIS) Preparation}

Bacillus anthracis 34F2 spores from Onderstepoort Biological Products (OBP), South Africa, batch 863 , was cultured as described by [16] and used to produce FIS for the vaccine. The spores were resuspended in PBS/0.1 g gelatin and stored at $-80^{\circ} \mathrm{C}$. Aliquots of the FIS suspension were tested for sterility by plating-on blood agar after treatment with histidine to neutralize any remnant formalin. The spores used for in vivo mouse challenge were not inactivated with formalin.

\subsection{Formulation of Non-Living Anthrax Vaccine}

The formulation was produced in a large volume of $60 \mathrm{~mL}$ ( 60 doses) each for the crude and purified vaccine formulations. The antigens and PBS solution were ascetically pooled and mixed at $250 \mathrm{rpm}$ with a magnetic stirrer, while $50 \%$ adjuvant volume (alhydroge ${ }^{\circledR}$ ) was slowly added and stirred for $2 \mathrm{~h}$ at room temperature, followed by slowly adding the remaining 50\% adjuvant volume (emulsigen- $\mathrm{D}^{\circledR}$ ) which was stirred for $2 \mathrm{~h}$ at room temperature. The vaccine formulation was transferred into sterile HDPE vaccine vials $(10 \mathrm{~mL})$ and retention vials were sent for a quality control test at Design Biologix.

For the vaccine formulation, the rPA for both crude and purified concentration was determined with Pierce BCA protein assay kit (ThermoFisher Scientific) and the concentration of rPA for PrPA and CrPA vaccine formulations were calculated according to Supplementary Material 1 . Then, it was adjusted through the FIS ( $10^{8}$ spores) and adjuvants to a volume of $1 \mathrm{~mL}$. The aseptic vaccine formulation procedure was carried out according to the requirements for vaccines [48]. Briefly, the PrPA+FIS+adjuvants vaccine formulation constituted of $258 \mu \mathrm{L}$ of $290 \mu \mathrm{g} / \mathrm{mL} \operatorname{PrPA}(75 \mu \mathrm{g} r P A), 400 \mu \mathrm{L}$ of $2.5 \times 10^{8}$ spores suspension per $\mathrm{mL}\left(1 \times 10^{8}\right.$ spores), $330 \mu \mathrm{L}$ of adjuvants (Emulsigen-D ${ }^{\circledR} /$ Alhydroge $^{\circledR}$ 1:1) and $12 \mu \mathrm{L}$ PBS in the $1 \mathrm{~mL}$ dose recommended [48], whereas the CrPA+FIS+adjuvants vaccine formulation constituted of $517 \mu \mathrm{L}$ of $146 \mu \mathrm{g} / \mathrm{mL}$ of $\mathrm{rPA}$ CrPA $(75 \mu \mathrm{g} \mathrm{rPA}), 400 \mu \mathrm{L} 2.5 \times 10^{8}$ spore suspension $\left(1 \times 10^{8}\right.$ spores), $330 \mu \mathrm{L}$ of adjuvants (Emulsigen-D ${ }^{\circledR} /$ Alhydrogel $\left.^{\circledR} 1: 1\right)$ and $3 \mu \mathrm{L}$ PBS.

\subsection{Immunization Animal Experiment and Passive Mouse Protection Tests}

Cattle were screened for PA-reactive antibodies using the PA-ELISA. The cattle experiment was conducted on a farm where the animals were born and raised, as approved by the Director of Animal Health, South Africa under the biosecurity section 20 of the animal disease Act 35 of 1984 (registration number: 12/11/1/1/6). After subcutaneous treatment with $4 \mathrm{~mL}$ Ivermectin (Ivomec injection South African Reg. No. G1142 (Act 36/1947)) and intramuscular injection with $10 \mathrm{~mL}$ multivitamins (Kyroligo Reg No. G3087 (Act 36/174)), the cattle were randomly allocated to four different vaccination groups, with eight animals in each group, except for the negative control group consisting of four animals, according to the animal ethics approval (protocol number; V118-17 Amendment 1) (Table 2). The animals were fed ad libitum and examined daily by a veterinarian. One animal died (vaccine group 
(C4)) after serum was collected for week 12 during the experiment. The cause of death was diarrhoea caused by Escherichia coli infection, as revealed by the post-mortem examination and laboratory results.

Table 2. Animal trial vaccination, dosage and sampling schedules.

\begin{tabular}{|c|c|c|c|c|c|c|}
\hline \multirow{2}{*}{$\begin{array}{l}\text { Vaccine Groups and } \\
\text { Cattle Number (n) }\end{array}$} & \multirow{2}{*}{ Vaccine and Dose } & \multicolumn{4}{|c|}{ Cattle Vaccination and Sampling Schedule } & \multirow{2}{*}{$\begin{array}{l}\text { A/J Mice Used in Passive } \\
\text { Mouse Challenge (n) }\end{array}$} \\
\hline & & Wk 0 & Wk 3 & Wk 5 & Wk 12 & \\
\hline SLSV $(\mathrm{n}=8)$ & $\begin{array}{l}\text { SLSV vaccine with } \\
\text { Anthravax }{ }^{\circledR} \\
\left(10^{8} \text { spores }\right)\end{array}$ & \pm & \pm & + & + & $\begin{array}{l}5 \text { mice/serum sample } \\
\qquad(\mathrm{n}=40)\end{array}$ \\
\hline $\operatorname{PrPA}+\mathrm{FIS}(\mathrm{n}=8)$ & $\begin{array}{c}\text { Purified rPA }(75 \mu \mathrm{g})+\text { FIS } \\
\left(10^{8} \text { spores }\right)+ \\
\text { Emulsigen-D }{ }^{\circledR} / \text { Alhydrogel }{ }^{\circledR} \\
\text { adjuvants }(33 \% \mathrm{v} / \mathrm{v})\end{array}$ & \pm & \pm & + & + & $\begin{array}{l}5 \text { mice } / \text { serum sample } \\
\qquad(\mathrm{n}=40)\end{array}$ \\
\hline CrPA+FIS $(n=8)$ & $\begin{array}{c}\text { Crude rPA }(75 \mu \mathrm{g})+\text { FIS } \\
\left(10^{8} \text { spores }\right)+ \\
\text { Emulsigen-D }{ }^{\circledR} / \text { Alhydrogel }{ }^{\circledR} \\
\text { adjuvants }(33 \% \mathrm{v} / \mathrm{v})\end{array}$ & \pm & \pm & + & + & $\begin{array}{l}5 \text { mice } / \text { serum sample } \\
\qquad(\mathrm{n}=40)\end{array}$ \\
\hline $\operatorname{NegCtl}(n=4)$ & $\begin{array}{c}\text { Emulsigen-D }{ }^{\circledR} / \text { Alhydrogel }{ }^{\circledR} \\
\text { adjuvants/saline }(33 \% \mathrm{v} / \mathrm{v})\end{array}$ & \pm & \pm & + & + & $\begin{array}{l}3 \text { mice/serum sample } \\
(\mathrm{n}=12)\end{array}$ \\
\hline
\end{tabular}

The two-step vaccine schedule of the cattle included vaccination at week 0 and week $3 . \pm$; Blood collection before vaccination, +; Blood collection, SLSV; Sterne live spore vaccine, PrPA; Purified recombinant protective antigen, $\mathrm{CrPA}$; Crude recombinant protective antigen, FIS; Formaldehyde inactivated spores, NegCtl: Negative control.

The passive mouse protection test was conducted in the Onderstepoort Veterinary animal research unit (OVARU) facility, University of Pretoria, South Africa in accordance with ethical principles and guidelines provided by the animal ethical committee of the University of Pretoria (protocol number; V118-17, Amendment 1) and section 20, Act 35 of 1984 permission granted by the Directorate of Animal Health of South Africa (registration number; 12/11/1/1/6(909). The passive protection test challenge model consisted of naïve inbred A/J mice from Jackson Laboratory, Bar Harbor, ME, USA. The A/J mouse strain lacks the $\mathrm{Hc}$ gene encoding for complement component 5 (C5), which renders it vulnerable to systemic infection with the B. anthracis 34F2 Sterne vaccine strain spores [16]. The experimental design consisting of five mice per vaccinated cattle serum and three mice per negative control cattle is shown in Table 2. For the passive protection test, IgG was purified from sera collected from the vaccine groups at week 5 , using the protein $\mathrm{G}$ spin column according to manufacturer's instruction ( $\mathrm{NAb}^{\mathrm{TM}}$ Protein G Spin Kit, Thermo Scientific). The presence of anti-rPA specific IgG was confirmed using ELISA and the concentration of the IgG was measured with Pierce BCA protein assay kit (ThermoFisher Scientific). Purified IgG (500 $\mu \mathrm{g}$ ) [49] was injected intraperitoneally into naïve A/J mice. The lethal challenge consisted of $2.16 \times 10^{5} \mathrm{~B}$. anthracis $34 \mathrm{~F} 2$ strain spores in $200 \mu \mathrm{L}$ injected through subcutaneous route, $24 \mathrm{~h}$ after the transfer of bovine polyclonal IgG. The A/J mice were monitored for clinical signs of anthrax intoxication for 14 days. Bacilli Giemsa stained smears and B. anthracis cultures from non-surviving A/J mice kidney, liver, and spleen on sheep blood agar were used to confirm death due to anthrax. Surviving mice were euthanized after 14 days by isoflurane overdose.

\subsection{Serum Immunoglobulin Titre Determination}

Anti-rPA and anti-FIS antibodies (IgM, IgG, IgG1 and IgG2) sera titre from vaccinated cattle were determined by ELISA as previously described by Ndumnego et al. [16]. Briefly, 96-wells microtitre plates (Nunc immunoplate Maxisorp) were coated with $0.5 \mu \mathrm{g}$ of rPA or $10^{8}$ FIS in carbonate-biocarbonate buffer (Sigma-Aldrich, USA) and incubated overnight at $4{ }^{\circ} \mathrm{C}$. Plates were washed twice with wash buffer (PBS + 0.05\% Tween 20 (PBST)) with ELISA microplate washer (Biorad PW40 France) and blocked with blocking buffer (PBST $+5 \%$ skimmed milk powder (PBSTM)) and incubated for $1 \mathrm{~h}$ at room temperature. Plates were washed twice and sera were added to the plate in duplicates across the plate at the starting concentration for IgG 1:100 and 1:50 for IgM and the immunoglobulin subclasses (IgG1 and IgG2) using PBSTM as sample dilution buffer. The plate was incubated on a shaking incubator at $160 \mathrm{rpm}$ for $30 \mathrm{~min}$ at room temperature and washed five times. Each plate was conjugated 
with the appropriate secondary antibody. For IgG, the secondary antibody (goat anti-bovine IgG (ThermoFisher Scientific)) was diluted at the concentration of 1:10,000 in PTSMP, whereas for IgM, IgG1 and IgG2, sheep anti-bovine IgM (ThermoFisher Scientific), and sheep anti-bovine IgG1 and IgG2 (ThermoFisher Scientific) were all diluted at 1:4000 in PTSMP, respectively. This was followed by $30 \mathrm{~min}$ incubation at room temperature in a shaking incubator (160 rpm). After washing five times, the plates were developed with 2,2' azino bis (3 ethylbenzthiazoline-6-sulfonic acid) diammonium salt (Sigma-Aldrich, St Louis, MO, USA) and absorbance readings taken on Biotek Powerwave XS2 reader at $405 \mathrm{~nm}$. The reciprocal of the nearest serum dilution above the cut-off optical density (mean optical density of negative control serum $+3 \mathrm{SD}$ ) was considered as the endpoint titre of individual serum. Titres of $<50$ for IgM, IgG1, IgG2 and IgG were ascribed an arbitrary value of 10 . The positive control was obtained from hyperimmune Sterne vaccinated animals that survived a virulent $B$. anthracis spores challenge [11] and the negative control is the pool of serum from pre-vaccination screened sera.

\subsection{Toxin Neutralization Assay (TNA)}

The functional ability of antibodies from vaccinated cattle and controls to neutralize anthrax lethal toxin was assessed using an in vitro TNA, as previously described by Ndumnego et al. [16]. The TNA was determined with J774A.1 mouse macrophage cells (ECACC cat no 91051511) exposed to anthrax lethal toxin in the presence of antibodies. Briefly, $1.0 \times 10^{5} \mathrm{~J} 774 \mathrm{~A} .1$ macrophages per well in Dulbecco's Modified Eagle Media (DMEM) and $10 \%$ foetal bovine serum (FBS) were incubated at $37^{\circ} \mathrm{C}$ and $5 \% \mathrm{CO}_{2}$ overnight in 96-well cell culture plates. Sera from each animal were 2-fold serially diluted in duplicates with the starting dilution of 1:50 in DMEM formulated with 5\% FBS containing PA ( $500 \mathrm{ng} / \mathrm{mL}$ ) and LF (400 ng/mL) (List Biological Laboratories Inc, Campbell, CA, USA) for $1 \mathrm{~h}$ at $37^{\circ} \mathrm{C}$ and $5 \% \mathrm{CO}_{2}$ before addition to the overnight-cultured confluent J774A.1 mouse macrophages and incubated for $3 \mathrm{~h}$. Thereafter, $25 \mu \mathrm{L}$ of $5 \mathrm{mg} / \mathrm{mL}$ MTT (3-(4,5 dimethylthiazol-2-yl)-2,5-diphenyltetrazolium bromide (Invitrogen) per well was added and incubated for $2 \mathrm{~h}$ at $37^{\circ} \mathrm{C}$ and $5 \% \mathrm{CO}_{2}$ in darkness. Acidified isopropanol (100 $\mu \mathrm{l}$ of $90 \%$ isopropyl alcohol, $0.5 \%$ SDS, $25 \mathrm{mM} \mathrm{HCl})$ was added to each well of the plate, followed by pipetting up and down to dissolve the formazan crystals dye. Finally, the plates were rested for $5 \mathrm{~min}$ and the absorbance read at $540 \mathrm{~nm}$ with a Biotek power wave XS2 reader. The neutralization of each serum sample was calculated using the formula:

$$
N T_{50}=\frac{(\text { sample }- \text { toxin control })}{(\text { medium control }- \text { toxin control })} \times 100
$$

The neutralization titres $\left(\mathrm{NT}_{50}\right)$ were expressed as the reciprocal of the highest serum dilution at which the J774A.1 macrophage cells survival yielded 50\% neutralization using the Gen 5 data analysis software (Biotek Instruments).

\subsection{Opsonophagocytic Assay}

The opsonophagocytic potential of induced antibodies was evaluated on RAW 264.7 macrophage cells as previously described with few modifications [50]. Briefly, heat-activated, refractile ungerminated B. anthracis spores $\left(2.6 \times 10^{9}\right.$ spores $\left./ \mathrm{mL}\right)$ were pre-incubated with 10 -fold serial dilutions of the immune sera and sera from the negative control (NegCtl), for $30 \mathrm{~min}$ in $4{ }^{\circ} \mathrm{C}$ and then added to RAW 264.7 macrophage cells $\left(5 \times 10^{5}\right.$ cells/well $)$ and incubated for $45 \mathrm{~min}$ at $37^{\circ} \mathrm{C}$ in $5 \% \mathrm{CO}_{2}$. The macrophage cells were washed with sterile PBS ( $\mathrm{pH} 7.4 \pm 1$ ) and incubated with DMEM containing 10\% FBS and $10 \mu \mathrm{g} / \mathrm{mL}$ gentamicin at $37^{\circ} \mathrm{C}$ in $5 \% \mathrm{CO}_{2}$ for $30 \mathrm{~min}$ to remove vegetative bacilli. Subsequently, the macrophage cells were washed with sterile ice-cold PBS, incubated for $5 \mathrm{~min}$ in $100 \mu \mathrm{L} 0.1 \%$ Triton $囚 \times 100$ (ThermoFisher Scientific) to lyse the macrophages and plated on LB media to count viable cfu/mL. Data are presented as percentage spore uptake by the macrophage cells. Sera from pre-vaccination screening was used as the negative control, whereas the group vaccinated with SLSV from this study was used as the positive control. 


\subsection{Statistical Analysis}

Gen 5 data analysis software (Biotek Instruments, Winooski, VT, USA) was used to generate 4-parametre logistic curves for the ELISA and TNA titres. The collected data were log-transformed using GraphPad prism version 8.3.0 software. The antibody titres between groups at different time points on ELISA and TNA were compared using unpaired Student $t$-test with a two-tailed $p$-value and Kruskal-Wallis test, followed by Dunn's multiple comparisons test with adjusted $p$-value, was utilized for intra-group comparisons. The mean survival time of the challenged A/J mice was plotted using the Kaplan-Meier survival curve. A log-rank (Mantel-Cox) test was used to compare survival between different vaccination groups. All graphical elucidations and the analysis were done using GraphPad prism version 8.3.0 software.

\section{Conclusions}

Our study demonstrates the potential of NLAV (PrPA+FIS or CrPA+FIS) formulated with combination adjuvants (Emulsigen-D ${ }^{\circledR} /$ Alhydroge $l^{\circledR}$ ) to induce an immune response against $B$. anthracis' toxins and spores in vaccinated cattle. The immune response by PrPA+FIS+Emulsigen-D ${ }^{\circledR} /$ Alhydroge ${ }^{\circledR}$ showed a significant level of protection in the passive mouse protection assay that is comparable to the SLSV. Because of the non-living feature of the vaccine, it is compatible with antibiotic treatment in the case of a disease outbreak. It can also be adopted for wildlife vaccination as well as in feedlots and is devoid of residual virulence in vaccinated animals. Finally, further study should compare the immunogenicity of NLAV with the current SLSV in field vaccination practice trials.

Supplementary Materials: The following are available online at http://www.mdpi.com/2076-0817/9/7/557/s1, Supplementary material S1: Purified and crude rPA calculation for vaccine formulation.

Author Contributions: Conceptualization: H.v.H., W.B. and O.C.N., Experiment conducted: S.J., A.B. and C.E. Data analysis: S.J. and O.C.N. Manuscript drafted: S.J. All authors have read and agreed to the published version of the manuscript.

Funding: The research was funded by Technology Innovation Agency (TIA) (Grant nr 90052) and National Research Foundation (NRF) South Africa (Grant nr 98651). TIA and NRF had no role in the study design, data collection and analysis, decision to publish, or preparation of the manuscript.

Acknowledgments: We would like to thank Design Biologix for providing cattle for trial and the quality control of the non-living anthrax vaccines formulated.

Conflicts of Interest: No conflict of interest was declared by all the authors.

\section{References}

1. Hambleton, P.; Carman, J.A.; Melling, J. Anthrax: The disease in relation to vaccines. Vaccine 1984, 2, 125-132. [CrossRef]

2. Beyer, W.; Turnbull, P. Anthrax in animals. Mol. Asp. Med. 2009, 30, 481-489. [CrossRef]

3. Cote, C.K.; Kaatz, L.; Reinhardt, J.; Bozue, J.; Tobery, A.S.; Bassett, D.A.; Sanz, P.; Darnell, C.S.; Alem, F.; O'Brien, D.A.; et al. Characterization of a multi-component anthrax vaccine designed to target the initial stages of infection as well as toxaemia. J. Med. Microbiol. 2012, 61, 1380-1392. [CrossRef] [PubMed]

4. Koehler, T. Bacillus anthracis genetics and virulence gene regulation, in Anthrax. Curr. Top. Microbiol. Immunol. 2002, 271, 143-164. [CrossRef]

5. Guidi-Rontani, C.; Weber-Levy, M.; Labruyère, E.; Mock, M. Germination of Bacillus anthracis spores within alveolar macrophages. Mol. Microbiol. 1999, 31, 9-17. [CrossRef]

6. Lacy, D.B.; Lin, H.C.; Melnyk, R.A.; Schueler-Furman, O.; Reither, L.; Cunningham, K.; Baker, D.; Collier, R.J. A model of anthrax toxin lethal factor bound to protective antigen. Proc. Natl. Acad. Sci. USA 2005, 102, 16409-16414. [CrossRef]

7. Leppla, S.H. Anthrax toxin edema factor: A bacterial adenylate cyclase that increases cyclic AMP concentrations of eukaryotic cells. Proc. Natl. Acad. Sci. USA 1982, 79, 3162-3166. [CrossRef] 
8. Mogridge, J.; Cunningham, K.; Lacy, D.B.; Mourez, M.; Collier, J.R. Biological Sciences-Microbiology-The lethal and edema factors of anthrax toxin bind only to oligomeric forms of the protective antigen. Proc. Natl. Acad. Sci. USA 2002, 99, 7045-7048. [CrossRef] [PubMed]

9. Stern, E.J.; Uhde, B.K.; Shadomy, V.S.; Messonnier, N. Conference report on public health and clinical guidelines for anthrax. Emerg. Infect. Dis. 2008, 14, e1. [CrossRef] [PubMed]

10. Sterne, M. The use of anthrax vaccines prepared from avirulent (uncapsulated) variants of Bacillus anthracis. Onderstepoort J. Vet. 1939, 13, 307-312.

11. Ndumnego, O.C.; Köhler, S.M.; Crafford, J.E.; van Heerden, H.; Beyer, W. Comparative analysis of the immunologic response induced by the Sterne 34F2 live spore Bacillus anthracis vaccine in a ruminant model. Vet. Immunol. Immunopathol. 2016, 178, 14-21. [CrossRef]

12. Fasanella, A.; Tonello, F.; Garofolo, G.; Muraro, L.; Carattoli, A.; Adone, R.; Muntecucco, C. Protective activity and immunogenicity of two recombinant anthrax vaccines for veterinary use. Vaccine 2008, 26, 5684-5688. [CrossRef] [PubMed]

13. Sterne, M. The immunization of laboratory animals against anthrax. Onderstepoort J. Vet. 1939, 13, 25.

14. Turnbull, P.C. Anthrax vaccines: Past, present and future. Vaccine 1991, 9, 533-539. [CrossRef]

15. Turnbull, P.C.B. Anthrax in Humans and Animals: Decisions on Treatment and/or Vaccination of Livestock; WHO: Geneva, Swtzerland, 2008; pp. 89-100.

16. Ndumnego, O.C.; Köhler, S.M.; Crafford, J.E.; Beyer, W.; van Heerden, H. Immunogenicity of anthrax recombinant peptides and killed spores in goats and protective efficacy of immune sera in A/J mouse model. Sci. Rep. 2018, 8, 16937. [CrossRef]

17. Brossier, F.; Levy, M.; Mock, M. Anthrax spores make an essential contribution to vaccine efficacy. Infect. Immun. 2002, 70, 661-664. [CrossRef]

18. Hahn, U.K.; Alex, M.; Czerny, C.-P.; Böhm, R.; Beyer, W. Protection of mice against challenge with Bacillus anthracis STI spores after DNA vaccination. Int. J. Med. Microbiol. 2004, 294, 35-44. [CrossRef]

19. Hahn, U.K.; Boehm, R.; Beyer, W. DNA vaccination against anthrax in mice-Combination of anti-spore and anti-toxin components. Vaccine 2006, 24, 4569-4571. [CrossRef]

20. Little, S.F.; Knudson, G.B. Comparative efficacy of Bacillus anthracis live spore vaccine and protective antigen vaccine against anthrax in the guinea pig. Infect. Immun. 1986, 52, 509-512. [CrossRef]

21. Parreiras, P.M.; Sirota, L.A.; Wagner, L.D.; Menzies, S.L.; Arciniega, J.L. Comparability of ELISA and toxin neutralization to measure immunogenicity of Protective Antigen in mice, as part of a potency test for anthrax vaccines. Vaccine 2009, 27, 4537-4542. [CrossRef]

22. Ribot, W.; Powell, B.S.; Ivins, B.E.; Little, S.F.; Johnson, W.M.; Hoover, T.A.; Norris, S.L.; Adamovicz, J.J.; Friedlander, A.M.; Andrews, G.P. Comparative vaccine efficacy of different isoforms of recombinant protective antigen against Bacillus anthracis spore challenge in rabbits. Vaccine 2006, 24, 3469-3476. [CrossRef]

23. Vance, D.J.; Rong, Y.; Brey, R.N.; Mantis, N.J. Combination of two candidate subunit vaccine antigens elicits protective immunity to ricin and anthrax toxin in mice. Vaccine 2015, 33, 417-421. [CrossRef]

24. Verma, A.; Burns, D.L. Improving the stability of recombinant anthrax protective antigen vaccine. Vaccine 2018, 36, 6379-6382. [CrossRef]

25. Koehler, S.M.; Buyuk, F.; Celebi, O.; Demiraslan, H.; Doganay, M.; Sahin, M.; Moehring, J.; Ndumnego, O.C.; Otlu, S.; van Heerden, H.; et al. Protection of farm goats by combinations of recombinant peptides and formalin inactivated spores from a lethal Bacillus anthracis challenge under field conditions. BMC Vet. Res. 2017, 13, 220-230. [CrossRef] [PubMed]

26. Kaur, M.; Saxena, A.; Rai, A.; Bhatnagar, R. Rabies DNA vaccine encoding lysosome-targeted glycoprotein supplemented with Emulsigen-D confers complete protection in preexposure and postexposure studies in BALB/c mice. FASEB J. 2010, 24, 173-183. [CrossRef] [PubMed]

27. McGonigle, J. Comparison of adjuvants for stimulation of HI antibody to SIV. In Proceedings of the 19th IPVS Congress, Copenhage, Denmark, 16-19 July 2006.

28. Shabana, W.; Ismail, H.M.; Mossad, W. Using Emulsigen-D as Recent Adjuvant in Trivalent Foot and Mouth Disease Vaccine. Glob. J. Med. Res. 2018, 18, 1-9.

29. Coffman, R.L.; Sher, A.; Seder, R.A. Vaccine adjuvants: Putting innate immunity to work. Immunity 2010, 33, 492-503. [CrossRef]

30. Gupta, R.K. Aluminum compounds as vaccine adjuvants. Adv. Drug Deliv. Rev. 1998, 32, 155-172. [CrossRef] 
31. Marrack, P.; McKee, A.S.; Munks, M.W. Towards an understanding of the adjuvant action of aluminium. Nat. Rev. Immunol. 2009, 9, 287-293. [CrossRef]

32. Nicol, J.; Sterne, M.L.M. The effect of large scale active immunization against anthrax. J. S. Afr. Vet. Assoc. 1942, 13, 53-63.

33. Webster, A. Inhibiting effect of antibiotics on anthrax vaccination. Aust. Vet. J. 1973, 49, 545. [CrossRef]

34. Ascough, S.; Ingram, R.J.; Chu, K.K.; Reynolds, C.J.; Musson, J.A.; Doganay, M.; Metan, G.; Metan, G.; Ozkul, Y.; Baillie, L.; et al. Anthrax lethal factor as an immune target in humans and transgenic mice and the impact of HLA polymorphism on CD4+ T cell immunity. PLoS Pathog. 2014, 10, e1004085. [CrossRef]

35. Brahmbhatt, T.N.; Darnell, S.C.; Carvalho, H.M.; Sanz, P.; Kang, T.J.; Bull, R.L.; Rasmussen, S.B.; Cross, A.S.; O'Brien, A.D. Recombinant exosporium protein BclA of Bacillus anthracis is effective as a booster for mice primed with suboptimal amounts of protective antigen. Infect. Immun. 2007, 75, 5240-5247. [CrossRef]

36. Duverger, A.; Carré, J.M.; Jee, J.; Leppla, S.H.; Cormet-Boyaka, E.; Tang, W.J.; Tomé, D.; Boyaka, P.N. Contributions of edema factor and protective antigen to the induction of protective immunity by Bacillus anthracis edema toxin as an intranasal adjuvant. J. Immunol. 2010, 185, 5943-5952. [CrossRef]

37. Enkhtuya, J.; Kawamoto, K.; Kobayashi, Y.; Uchida, I.; Rana, N.; Makino, S.; Makino, S. Significant passive protective effect against anthrax by antibody to Bacillus anthracis inactivated spores that lack two virulence plasmids. Microbiology 2006, 152, 3103-3110. [CrossRef]

38. Gauthier, Y.P.; Tournier, J.N.; Paucod, J.C.; Corre, J.P.; Mock, M.; Goossens, P.L.; Vidal, D.R. Efficacy of a vaccine based on protective antigen and killed spores against experimental inhalational anthrax. Infect. Immun. 2009, 77, 1197-1207. [CrossRef] [PubMed]

39. Majumder, S.; Das, S.; Somani, V.; Makam, S.S.; Joseph, K.J.; Bhatnagar, R. A bivalent protein r-PB, comprising $\mathrm{PA}$ and BclA immunodominant regions for comprehensive protection against Bacillus anthracis. Sci. Rep. 2018, 8, 7242. [CrossRef]

40. Majumder, S.; Majumder, S.; Das, S.; Somani, K.V.; Makam, S.S.; Joseph, K.J.; Bhatnagar, R. A bivalent protein $\mathrm{r}$-PAbxpB comprising PA domain IV and exosporium protein BxpB confers protection against B. anthracis spores and toxin. Front. Immunol. 2019, 10, 498. [CrossRef]

41. Little, S.F.; Ivin, B.E.; Friedlander, A.M. Passive protection by polyclonal antibodies against Bacillus anthracis infection in guinea pigs. Infect. Immun. 1997, 65, 5171-5175. [CrossRef]

42. Little, S.F.; Leppla, S.H.; Cora, E. Production and characterization of monoclonal antibodies to the protective antigen component of Bacillus anthracis toxin. Infect. Immun. 1988, 56, 1807-1813. [CrossRef]

43. Vergis, J.M.; Cote, C.K.; Bozue, J.; Alem, F.; Ventura, C.L.; Welkos, S.L.; O’Brien, A.D. Immunization of mice with formalin-inactivated spores from avirulent Bacillus cereus strains provides significant protection from challenge with Bacillus anthracis Ames. Clin. Vaccine Immunol. 2013, 20, 56-65. [CrossRef]

44. Mittenbühler, K.; v d Esche, U.; Heinevetter, L.; Bessler, W.G.; Huber, M. Lipopeptides: Adjuvanticity in conventional and genetic immunization. FEMS Immunol. Med. Microbiol. 2003, 37, 193-200. [CrossRef]

45. Welkos, S.L.; Friedlander, A.M. Comparative safety and efficacy against Bacillus anthracis of protective antigen and live vaccines in mice. Microb. Pathog. 1988, 5, 127-139. [CrossRef]

46. Crowe, S.R.; Ash, L.L.; Engler, R.J.; Ballard, J.D.; Harley, J.B.; Farris, A.D.; James, J.A. Select human anthrax protective antigen epitope-specific antibodies provide protection from lethal toxin challenge. J. Infect. Dis. 2010, 202, 251-260. [CrossRef] [PubMed]

47. Casadevall, A. Antibody-based defense strategies against biological weapons. ASM News 2005, 71, 28-33.

48. OIE. Manual of Diagnostic Tests and Vaccines for Terrestrial Animals (Mammals, Birds and Bees): Anthrax. Ch. 2.1.1; Office International des Épizooties: Paris, France, 2012; Volume 1, pp. 555-574.

49. Williamson, E.D.; Hodgson, I.; Walker, N.J.; Topping, A.W.; Duchars, M.G.; Mott, M.J.; Estep, J.; LeButt, C.; Flick-Smith, C.H.; Jones, E.H.; et al. Immunogenicity of recombinant protective antigen and efficacy against aerosol challenge with anthrax. Infect. Immun. 2005, 73, 5978-5987. [CrossRef]

50. Welkos, S.; Little, S.; Friedlander, A.; Fritz, D.; Fellows, P. The role of antibodies to Bacillus anthracis and anthrax toxin components in inhibiting the early stages of infection by anthrax spores. Microbiology 2001, 147, 1677-1685. [CrossRef]

(C) 2020 by the authors. Licensee MDPI, Basel, Switzerland. This article is an open access article distributed under the terms and conditions of the Creative Commons Attribution (CC BY) license (http://creativecommons.org/licenses/by/4.0/). 